\title{
A Single Intravenous Dose of Ivabradine, a Novel If Inhibitor, Lowers Heart Rate but Does Not Depress Left Ventricular Function in Patients with Left Ventricular Dysfunction
}

\author{
Matthias Manz ${ }^{a}$ Marcus Reuter ${ }^{a}$ Gerhard Lauck ${ }^{a}$ Hegder Omran ${ }^{b}$ \\ Werner Jung ${ }^{b}$ \\ aDepartment of Cardiology, Marienhof Hospital, Koblenz, ${ }^{\mathrm{b}}$ Departments of Medicine and Cardiology, \\ University of Bonn, Bonn, Germany
}

\section{Key Words}

Left ventricular dysfunction . Heart rate

Echocardiography · Left ventricular ejection fraction •

Stroke volume $\cdot I_{f}$ inhibitor $\cdot$ Ivabradine

\begin{abstract}
This randomized, single-blind, placebo-controlled study investigated the effect of ivabradine, a novel heart ratelowering agent, on echocardiographic indices of left ventricular (LV) systolic function in patients with regional (coronary artery disease) or global (cardiomyopathy) LV dysfunction. Patients were randomized on an unequal basis to receive ivabradine $0.25 \mathrm{mg} / \mathrm{kg}(\mathrm{n}=31)$ or placebo ( $n=13$ ) by intravenous infusion. Resting heart rate was reduced by a mean of $17.6 \pm 4.7 \%$ with ivabradine and $1.5 \pm 5.8 \%$ with placebo. The mean maximum decrease in LV ejection fraction was $0.2 \%$ with ivabradine and $1.7 \%$ with placebo. Fractional shortening and stroke vol-
\end{abstract}

The authors have a research relationship with a profit organization (Institut de Recherches Internationales Servier, Courbevoie, France). ume were also fully preserved after ivabradine administration. Thus, a single intravenous dose of ivabradine produced a substantial reduction in resting heart rate without affecting LV function in patients with regional or global LV dysfunction.

Copyright @ 2003 S. Karger AG, Basel

\section{Introduction}

Stable angina pectoris is a common and disabling condition that is usually caused by atheromatous narrowing of the coronary arteries. Symptoms occur when coronary blood flow is unable to meet an increase in myocardial oxygen demand triggered by physical exertion or emotional stress. Drugs that lower heart rate can prevent anginal symptoms by increasing coronary blood flow by lengthening the diastolic filling period, and by reducing myocardial oxygen demand. Beta-blocking agents are widely used in stable angina [1]. However, in addition to reducing heart rate, beta-blockers also acutely reduce myocardial contractility and depress left ventricular (LV) function [2-5], effects which may be undesirable in some circumstances, particularly in patients whose ventricular function is already impaired.

Prof. Dr. M. Manz

Krankenhaus Marienhof, Innere Medizin, Kardiologie

Rudolf-Virchow-Strasse 7

DE-56065 Koblenz (Germany)

Tel. +49 26149631 31, Fax +4926149631 33, E-Mail innere@kk-koblenz.de 
Ivabradine (Procoralan, S 16257, Servier, France) is a member of a new class of selective heart rate-lowering agents. Ivabradine exerts its effect by inhibiting an important pacemaker current $\left(I_{f}\right)$ in the sinoatrial node [6-9]. Ivabradine produces dose-dependent reductions in heart rate in experimental animals [10-13] and healthy volunteers [14] and in patients with chronic stable angina [15]. In conscious dogs, ivabradine reduces heart rate without any negative inotropic effect, both at rest and during treadmill exercise [13].

The antianginal and anti-ischemic efficacy of ivabradine was investigated in a randomized, double-blind, placebo-controlled trial in patients with chronic stable angina [15]. Ivabradine produced dose-dependent improvements in time to 1-mm ST segment depression and time to limiting angina during bicycle exercise. Reductions in angina attack rate and short-acting nitrate use were also observed.

The aim of this study was to investigate the effect of ivabradine on echocardiographic indices of LV systolic function in patients with abnormal baseline LV function due to cardiomyopathy or coronary artery disease.

\section{Methods}

\section{Patients}

Hospitalized or outpatient adults were included in the study if they were under 75 years of age and had LV dysfunction [angiographic, radionuclide or echocardiographic LV ejection fraction (LVEF) $20-50 \%$ within 3 months prior to the study]. Women had to have no child-bearing potential. Postmenopausal women under 60 years of age had to be negative for follicle-stimulating hormone and estradiol. Additional inclusion criteria were: usually in sinus rhythm; stable cardiac disease status during the preceding 3 months; not treated with beta-blockers, calcium antagonists or digitalis glycosides for at least five half-lives of the drugs; resting heart rate $\geq 60 \mathrm{bpm}$; systolic blood pressure in supine position $\geq 100 \mathrm{~mm} \mathrm{Hg}$; normal blood hematology and chemistry; normal liver function tests; serum creatinine $<1.5$ times normal upper limit value; normal prothrombin and activated partial thromboplastin times.

Patients were not selected if they fulfilled any of the following criteria: contraindication for heart rate-lowering agents; requiring or in receipt of antiarrhythmic drugs during the previous five half-lives of the drugs; history of drug allergy or hypersensitivity; not amenable to accurate echocardiography; concomitant treatment with investigational drugs or nonprescription drugs during the previous 2 months; history of severe visual acuity deficit.

Patients were stratified according to their type of LV dysfunction. Patients with regional LV dysfunction (coronary artery disease) had to have a documented history of acute myocardial infarction, abnormal Q wave on electrocardiography (ECG) or coronary angiography demonstrating the presence of coronary artery disease with significant stenosis or occlusion, together with regional wall motion abnormality described as hypokinesis, akinesis or dyskinesis on a previous angiography, radionuclide or echocardiography examination. Patients with global LV dysfunction (cardiomyopathy) had to have an enlarged ventricle ( $\mathrm{LV}$ internal end-diastolic dimension on parasternal short axis view $>2.7 \mathrm{~cm} / \mathrm{m}^{2}$ ), with no evidence of significant coronary artery disease and no history of hypertension, valvular or pericardial disease, or arrhythmia, and no congenital anatomical abnormalities.

\section{Study Design}

This was a randomized, single-blind, placebo-controlled study carried out at two sites in Germany. Patients underwent a screening visit 14 days before inclusion, then were hospitalized for inclusion, study drug administration and investigations on day 0 (D0) and a safety examination on day 1 (D1), $24 \mathrm{~h}$ after treatment administration, followed by discharge from the hospital. Patients were randomized to receive either ivabradine $0.25 \mathrm{mg} / \mathrm{kg}$ or placebo, on an unequal basis ( 3 ivabradine: 1 placebo). Treatments were administered by intravenous infusion over $1 \mathrm{~h}$, after which the patients remained in a supine position for a further $3 \mathrm{~h}$. Heart rate was monitored during treatment administration, and the infusion was terminated in patients whose heart rate decreased to $80 \%$ of baseline values or to $45 \mathrm{bpm}$ before completion of the infusion. The investigators were aware of the nature of each patient's treatment before administration.

\section{Efficacy Measurements}

LV function was assessed by echocardiography, with LVEF as the primary evaluation criterion, and fractional shortening (FS) and stroke volume (SV) as secondary evaluation criteria.

Echocardiography (using a Wingman $800 \mathrm{C}, 3.5-\mathrm{MHz}$ transducer; Sonotron, Norway) was performed at the screening visit, on D0 prior to treatment administration (Echo 0), at the end of treatment administration (Echo 1) and $2 \mathrm{~h}$ after the end of administration (Echo 2).

LV end-diastolic (LVEDd) and end-systolic (LVEDs) dimensions were measured in M-mode recording, and FS was calculated as follows:

$$
\text { FS }(\%)=[(\text { LVEDd }- \text { LVEDs }) / \text { LVEDd }] \times 100 .
$$

LV end-diastolic volume (EDV) and end-systolic volume (ESV) were calculated from two-dimensional echo recordings, using the modified Simpson's rule approach. LVEF was calculated as follows:

$$
\operatorname{LVEF}(\%)=(\mathrm{SV} / \mathrm{EDV}) \times 100,
$$

where $\mathrm{SV}=\mathrm{EDV}-\mathrm{ESV}$.

Echocardiography recordings were assessed at the time of recording by the investigators, and also retrospectively by an investigator located in the other study center (cross-reading). The cross-reading investigator was blinded to the identity of the patient, the treatment administered, the timing of the recording (Echo 0,1 or 2) and the assessment of the other investigator. Only the results of the blinded cross-readings were used for statistical analysis of efficacy.

\section{Safety}

Safety monitoring included measurements of heart rate, blood pressure and respiratory rate before treatment and $24 \mathrm{~h}$ following treatment. Patients were also subjected to 12-lead ECG evaluations before the dose and $18 \mathrm{~h}$ after the dose. Continuous monitoring of blood pressure and ECG (using frontal leads) was carried out during the infusion and continued for $18 \mathrm{~h}$ after treatment. 
Table 1. Patient characteristics

\begin{tabular}{lcc}
\hline & $\begin{array}{l}\text { Ivabradine } \\
(\mathrm{n}=31)\end{array}$ & $\begin{array}{l}\text { Placebo } \\
(\mathrm{n}=13)\end{array}$ \\
\hline Mean age, years (range) & $59.6(32-75)$ & $60.1(35-78)$ \\
Mean weight, kg (range) & $78.5(50-112)$ & $69.6(39-115)$ \\
Mean height, cm (range) & $170.7(153-198)$ & $168.1(150-185)$ \\
Mean systolic blood pressure, mm Hg (range) & $127.8(100-160)$ & $128.1(110-145)$ \\
Mean diastolic blood pressure, mm Hg (range) & $79.8(60-100)$ & $74.6(60-95)$ \\
Mean heart rate \pm SD, bpm & $76.6 \pm 12.2$ & $74.4 \pm 12.8$ \\
ECG profile, $\mathrm{n}(\%)$ & & $10(76.9)$ \\
$\quad$ Subendocardial ischemia & $19(61.3)$ & $1(7.7)$ \\
Q wave anterior necrosis & $7(22.6)$ & $2(15.4)$ \\
Q wave inferior necrosis & $3(9.7)$ & 0 \\
Complete left BBB & $4(12.9)$ & \\
\hline
\end{tabular}

$\mathrm{BBB}=$ Bundle-branch block

\section{Statistical Analysis}

All patients treated with either ivabradine or placebo were included in the full-analysis population. The per protocol (PP) population was limited to patients who met all major inclusion criteria, and results for the PP population are presented here unless otherwise stated. All randomized and treated patients were included in the safety population.

The main efficacy assessment criteria were the maximum decreases in LVEF, FS and SV after treatment, calculated as the baseline value minus the lowest value recorded after infusion. A fixed model, with diagnosis or etiology and group effects, was used to estimate a $95 \%$ confidence interval for the differences between treatment groups, and for differences between patients with global versus regional LV dysfunction.

\section{Results}

\section{Patient Characteristics}

Forty-four patients (29 men, 15 women) were randomized and 43 patients completed the study. One patient experienced an adverse event (transient bradycardia) before study drug administration, and was withdrawn.

There were no significant differences between the ivabradine $(n=31)$ and placebo $(n=13)$ groups with regard to patient demographics or clinical characteristics, including heart rate and ECG profile (table 1). The most common ECG feature was subepicardial ischemia, which was detected in $61.3 \%$ of the patients in the treatment group and $76.9 \%$ of the patients in the placebo group. At Echo 0, prior to study drug administration, there were no significant differences between treatment groups in terms of the echocardiographic parameters LVEF, FS and SV.

Ivabradine Preserves Left Ventricular

Function
Ivabradine infusion was terminated early in 17 patients who showed a $20 \%$ decrease in heart rate or a heart rate of $45 \mathrm{bpm}$ before the full dose had been infused. The mean dose of ivabradine administered was $16.7 \mathrm{mg}$ (range $7-25 \mathrm{mg}$ ), corresponding to a dosage of $0.21 \pm 0.04 \mathrm{mg} /$ $\mathrm{kg}$.

Thirty-eight patients who met all the major inclusion criteria were included in the PP population. Five patients (3 randomized to ivabradine, 2 to placebo) were excluded from the PP population due to concurrent or prior treatment with digitoxin or digoxin.

\section{Efficacy}

Ivabradine administration produced a substantial reduction in heart rate. At the end of the infusion, heart rate was reduced by a mean of $17.6 \pm 4.7 \%$ relative to baseline in the ivabradine-treated group, compared with a reduction of $1.5 \pm 5.8 \%$ in the placebo group. Heart rate in the patients given ivabradine remained below baseline levels for up to $18 \mathrm{~h}$.

In the ivabradine-treated group of the PP population, LVEF, SV and stroke index tended to increase slightly between baseline and the second echocardiogram, and FS remained unchanged (table 2). In the placebo group, LVEF and FS remained unchanged, and SV and stroke index tended to decrease slightly (table 2). None of these changes were clinically significant.

The mean maximum decrease in LVEF from baseline was $0.2 \%$ in the ivabradine-treated group, compared with $1.7 \%$ in the placebo group (table 3). Changes in LVEF with ivabradine were similar in the cardiomyopathy and coronary artery disease subgroups (table 3 ). The 95\% con- 
Table 2. Evolution of echocardiographic parameters (PP population)

\begin{tabular}{llll}
\hline & & $\begin{array}{l}\text { Ivabradine } \\
(\mathrm{n}=27)\end{array}$ & $\begin{array}{l}\text { Placebo } \\
(\mathrm{n}=11)\end{array}$ \\
\hline LVEF, \% & Echo 0 & $34.3 \pm 7.8$ & $38.1 \pm 6.5$ \\
& Echo 1 & $35.0 \pm 10.4$ & $38.1 \pm 8.6$ \\
& Echo 2 & $37.2 \pm 10.1$ & $38.4 \pm 9.4$ \\
\hline FS, \% & Echo 0 & $19.5 \pm 8.5$ & $20.4 \pm 7.1$ \\
& Echo 1 & $20.9 \pm 9.3$ & $21.7 \pm 7.3$ \\
& Echo 2 & $19.3 \pm 8.0$ & $20.9 \pm 9.7$ \\
\hline SV, ml & Echo 0 & $63.0 \pm 21.2$ & $66.1 \pm 20.2$ \\
& Echo 1 & $63.9 \pm 21.1$ & $61.2 \pm 19.7$ \\
& Echo 2 & $66.6 \pm 19.3$ & $58.7 \pm 15.6$ \\
\hline Stroke index, $\mathrm{ml} / \mathrm{m}^{2}$ & Echo 0 & $32.6 \pm 10.5$ & $38.1 \pm 11.0$ \\
& Echo 1 & $32.8 \pm 9.7$ & $35.5 \pm 11.3$ \\
& Echo 2 & $34.2 \pm 8.8$ & $33.6 \pm 7.4$ \\
\hline LV EDV, $\mathrm{ml}$ & Echo 0 & $193 \pm 78$ & $177 \pm 60$ \\
& Echo 1 & $197 \pm 84$ & $167 \pm 55$ \\
& Echo 2 & $194 \pm 81$ & $158 \pm 49$ \\
\hline LV ESV, $\mathrm{ml}$ & Echo 0 & $130 \pm 64$ & $111 \pm 43$ \\
& Echo 1 & $133 \pm 72$ & $105 \pm 44$ \\
& Echo 2 & $127 \pm 71$ & $100 \pm 39$ \\
\hline
\end{tabular}

Values are expressed as mean $\pm \mathrm{SD}$.

Table 3. Effect of ivabradine on echocardiographic indices of LV function (PP population)

\begin{tabular}{|c|c|c|c|c|c|c|}
\hline & \multicolumn{2}{|l|}{ All patients } & \multicolumn{2}{|c|}{ Cardiomyopathy } & \multicolumn{2}{|c|}{ Coronary artery disease } \\
\hline & $\begin{array}{l}\text { ivabradine } \\
(\mathrm{n}=27)\end{array}$ & $\begin{array}{l}\text { placebo } \\
(\mathrm{n}=11)\end{array}$ & $\begin{array}{l}\text { ivabradine } \\
(\mathrm{n}=12)\end{array}$ & $\begin{array}{l}\text { placebo } \\
(\mathrm{n}=4)\end{array}$ & $\begin{array}{l}\text { ivabradine } \\
(\mathrm{n}=15)\end{array}$ & $\begin{array}{l}\text { placebo } \\
(\mathrm{n}=7)\end{array}$ \\
\hline \multicolumn{7}{|l|}{ LVEF, \% } \\
\hline Mean maximum decrease \pm SD & $0.2 \pm 5.3$ & $1.7 \pm 6.4$ & $0.0 \pm 5.6$ & $-0.05 \pm 7.1$ & $0.4 \pm 5.3$ & $3.0 \pm 6.2$ \\
\hline Difference $(95 \% \mathrm{CI})$ & \multicolumn{2}{|c|}{$-1.4[-5.6$ to 2.7$]$} & \multicolumn{2}{|c|}{$0.5[-6.9$ to 7.9$]$} & \multicolumn{2}{|c|}{$-2.7[-8.0$ to 2.7$]$} \\
\hline \multicolumn{7}{|l|}{$\mathrm{FS}, \%$} \\
\hline Mean maximum decrease \pm SD & $0.7 \pm 4.4^{1}$ & $1.7 \pm 5.1$ & $1.5 \pm 3.6$ & $1.1 \pm 5.4$ & $0.0 \pm 5.0^{2}$ & $2.0 \pm 5.4$ \\
\hline Difference $(95 \% \mathrm{CI})$ & \multicolumn{2}{|c|}{$-1.0[-4.4$ to 2.4$]$} & \multicolumn{2}{|c|}{$0.4[-4.7$ to 5.5$]$} & \multicolumn{2}{|c|}{$-1.9[-6.9$ to 3.1$]$} \\
\hline \multicolumn{7}{|l|}{$\mathrm{SV}, \mathrm{ml}$} \\
\hline Mean maximum decrease \pm SD & $2.4 \pm 15.4$ & $12.2 \pm 16.1$ & $4.0 \pm 18.5$ & $0.6 \pm 15.4$ & $1.2 \pm 12.9$ & $18.8 \pm 13.3$ \\
\hline Difference $(95 \% \mathrm{CI})$ & \multicolumn{2}{|c|}{$-9.5[-20.9$ to 2.0$]$} & \multicolumn{2}{|c|}{$3.4[-18.8$ to 25.6$]$} & \multicolumn{2}{|c|}{$-17.6[-30.0$ to -5.1$]$} \\
\hline \multicolumn{7}{|c|}{$\begin{array}{l}\text { Values represent mean maximum decrease from baseline. } \mathrm{CI}=\text { Confidence interval. } \\
1 \mathrm{n}=26 \text {. }\end{array}$} \\
\hline $2 \mathrm{n}=14$ & & & & & & \\
\hline
\end{tabular}

fidence intervals all showed nonsignificance for the difference between the ivabradine and placebo groups.

The mean maximum decrease in FS was $0.7 \%$ in the ivabradine group and $1.7 \%$ with placebo (table 3 ). Again, results for the cardiomyopathy and coronary artery dis- ease subgroups were similar, none of the changes were clinically relevant and the $95 \%$ confidence intervals all showed nonsignificance for the difference between the ivabradine and placebo groups. 
The mean maximum decrease in SV was $2.4 \mathrm{ml}$ in the ivabradine group, compared with $12.2 \mathrm{ml}$ in the placebo group (table 3 ). The decrease in mean maximum SV seen in the placebo group was largely due to a pronounced decrease seen in the coronary artery disease subgroup (table 3). In this subgroup, the difference between the ivabradine and placebo groups was significant.

LV EDV and ESV remained stable after ivabradine treatment, but both parameters tended to decrease after placebo (table 2). There were no relevant changes in LVEDd and LVEDs after either treatment (data not shown).

In the PP population, there was a negative correlation between LVEF at Echo 1 and heart rate at the end of the infusion in both the ivabradine $(\mathrm{r}=-0.422)$ and placebo groups $(r=-0.231)$. There was no correlation $(r=-0.002)$ between LVEF at Echo 1 and the dose of ivabradine administered (patients randomized to placebo were counted as having received a zero dose of ivabradine).

For all echocardiographic parameters measured, the results for the full-analysis population were similar to those reported above for the PP population.

\section{Safety}

No serious or severe adverse events occurred during the study. Adverse events were seen in 9 patients (30\%) in the ivabradine treatment group and in 2 patients $(15 \%)$ in the placebo group. The most common adverse event was headache, which occurred in 2 patients in the ivabradine group and 1 patient in the placebo group. Adverse events judged to be possibly related to ivabradine treatment were experienced by 4 patients, and included atrial fibrillation detected on the day of treatment in 1 patient, which resolved with symptomatic treatment on the same day. The other treatment-related adverse events were mild headache in 1 patient on D0, and mild visual symptoms in 2 patients on D1, all of which resolved spontaneously within a day.

There were no clinically relevant changes in ECG parameters between inclusion, D0 and D1 in either treatment group. Diastolic and systolic blood pressures were also similar at the beginning and end of the infusion in both treatment groups. There was no laboratory evidence of significant ivabradine-related hematological or biochemical alterations.

\section{Discussion}

This study showed that single intravenous administrations of ivabradine produced pronounced reductions in heart rate in patients with LV dysfunction, without altering echocardiographic indicators of LV function. Heart rate at rest was reduced by a mean of $17.6 \%$ in the ivabradine treatment group, compared with a reduction of $1.5 \%$ in the placebo group. This reduction in heart rate is comparable with that previously reported for ivabradine in healthy volunteers [14] and in patients with chronic stable angina [15]. Ivabradine $10 \mathrm{mg}$ twice a day reduced resting heart rate at trough of drug activity by $18 \%$ in patients with chronic stable angina [15].

All the echocardiographic parameters measured in the present study, including LVEF, FS and SV, were fully preserved after ivabradine administration. None of the changes in these parameters was either statistically significant or clinically relevant; indeed, several parameters increased slightly, relative to placebo, after ivabradine. Preservation of LV function was seen in both the subgroup of patients with global LV dysfunction related to cardiomyopathy, and the subgroup of patients with regional LV dysfunction associated with coronary artery disease.

The reduction in heart rate with preservation of $\mathrm{LV}$ function seen with ivabradine administration is in contrast to the acute actions of beta-blocking agents, which generally show both negative chronotropic and inotropic effects. For example, a single intravenous administration of propranolol $(0.15 \mathrm{mg} / \mathrm{kg})$ has been reported to reduce resting SV and LVEF as well as heart rate in patients with stable angina [16]. Atenolol has been reported to decrease both diastolic and systolic parameters of LV performance in hypertensive patients [5]. Additionally, in an experimental model of acute LV failure in dogs, intravenous propranolol significantly decreased the performance of the failing ventricle [17]. Not all beta-blockers impair LV function to the same extent. In particular, beta-blocking agents with intrinsic sympathomimetic activity, such as oxprenolol, pindolol and practolol, may depress LV function to a lesser degree than agents that lack this activity, such as propranolol and metoprolol [2, 18]. Although beta-blocker treatment has been shown to be of long-term benefit in heart failure patients, initial depression of LV function may be undesirable in some circumstances, and careful dose titration may therefore be needed at the initiation of treatment.

In the present study, a single intravenous administration of ivabradine produced a long-lasting reduction in 
heart rate, detectable for up to $18 \mathrm{~h}$ after the end of the infusion. It has been suggested that the initial heart ratelowering action is associated with the active N-dealkylated metabolite (S 18982) of ivabradine, whereas the subsequent, relatively long duration of action is caused by the parent drug [14].

Ivabradine is a selective and specific inhibitor of $I_{f}$, which is a hyperpolarization-activated, mixed sodium/ potassium inward current involved in pacemaking in the sinoatrial node [7]. In animal studies, it has been shown that ivabradine at therapeutic concentrations has little action on other cardiac ionic currents or cardiac action potential shape $[9,10]$. This specificity of action may underlie the lack of effect of ivabradine on myocardial contractility observed in animal studies [11, 13, 19], and on LV performance, as demonstrated in the present study.

Cardiac $\mathrm{I}_{\mathrm{f}}$ channels are modulated by the intracellular cAMP concentration, which may be an important mechanism for the physiological alteration of heart rate [20-22]. $\mathrm{I}_{\mathrm{f}}$ in both isolated rat ventricular myocytes [23] and human atrial myocytes [24] is modulated by beta-adrenoceptor stimulation. The heart rate-lowering action of betablockade may, at least in part, be mediated via modulation of $I_{f}$. However, direct and specific inhibition of $I_{f}$ channels by an agent such as ivabradine may allow a reduction in heart rate to be achieved with minimal alteration of other myocardial properties.

The clinical safety of ivabradine was good, with no serious or severe adverse events reported in this study. Four adverse events possibly related to ivabradine administration were reported: 1 case of headache, 1 case of transient atrial fibrillation, and 2 cases of transient visual symptoms. The visual symptoms were expected, having been reported previously in healthy volunteers [14], and may be linked to the presence in the retina of ion channels similar to those mediating $\mathrm{I}_{\mathrm{f}}$ [25-27].

In conclusion, a single intravenous administration of ivabradine, at a dose that produced a substantial reduction in heart rate, produced no alterations in echocardiographic indices of $\mathrm{LV}$ function in patients with regional or global LV dysfunction. These properties may make ivabradine a valuable alternative to existing drug therapy for stable angina and other ischemic myocardial conditions.

\section{Acknowledgement}

This study was supported by Institut de Recherches Internationales Servier, Courbevoie, France.

\section{References}

1 Management of stable angina pectoris. Recommendations of the Task Force of the European Society of Cardiology. Eur Heart J 1997;18: 394-413.

2 Taylor SH, Silke B, Lee PS: Intravenous betablockade in coronary heart disease: Is cardioselectivity or intrinsic sympathomimetic activity hemodynamically useful? $\mathrm{N}$ Engl J Med 1982;306:631-635.

3 Silke B, Nelson GI, Ahuja RC, Taylor SH: Comparative haemodynamic dose response effects of propranolol and labetolol in coronary heart disease. Br Heart J 1982;48:364-371.

4 Nigri A, Mangieri E, Martuscelli E, Reale A: Acute hemodynamic effects of acebutolol and propranolol. Clin Ther 1984;6:693-698.

5 Zusman RM, Christensen DM, Higgins J, Boucher CA: Comparison of the cardiac and hemodynamic effects of lisinopril and atenolol in patients with hypertension: Therapeutic implications. J Cardiovasc Pharmacol 1992;20: 216-222.

6 DiFrancesco D: Characterization of single 'pacemaker' channels in cardiac sino-atrial node cells. Nature 1986;324:470-473.

7 DiFrancesco D: The contribution of the pacemaker current $\left(\mathrm{I}_{\mathrm{f}}\right)$ to generation of spontaneous activity in rabbit sino-atrial node myocytes. J Physiol 1991;434:23-40.
8 Irisawa H, Brown HF, Giles W: Cardiac pacemaking in the sinoatrial node. Physiol Rev 1993; 73:197-227.

9 Bois P, Bescond J, Renaudon B, Lenfant J: Mode of action of bradycardic agent, S 16257, on ionic currents of rabbit sinoatrial node cells. Br J Pharmacol 1996;118:1051-1057.

10 Thollon C, Cambarrat C, Vian J, Prost JF, Peglion JL, Vilaine JP: Electrophysiological effects of S 16257, a novel sino-atrial node modulator, on rabbit and guinea-pig cardiac preparations: Comparison with UL-FS 49. Br J Pharmacol 1994;112:37-42.

11 Gardiner SM, Kemp PA, March JE, Bennett T: Acute and chronic cardiac and regional haemodynamic effects of the novel bradycardic agent, $\mathrm{S} 16257$, in conscious rats. $\mathrm{Br} \mathrm{J}$ Pharmacol 1995; 115:579-586.

12 Perez O, Gay P, Franqueza L, Carron R, Valenzuela C, Delpon E, Tamargo J: Effects of the two enantiomers, S-16257-2 and S-16260-2, of a new bradycardic agent on guinea-pig isolated cardiac preparations. $\mathrm{Br} \mathrm{J}$ Pharmacol 1995; 115:787-794.

13 Simon L, Ghaleh B, Puybasset L, Giudicelli JF, Berdeaux A: Coronary and hemodynamic effects of S 16257, a new bradycardic agent, in resting and exercising conscious dogs. J Pharmacol Exp Ther 1995;275:659-666.
14 Ragueneau I, Laveille C, Jochemsen R, Resplandy G, Funck-Brentano C, Jaillon P: Pharmacokinetic-pharmacodynamic modeling of the effects of ivabradine, a direct sinus node inhibitor, on heart rate in healthy volunteers. Clin Pharmacol Ther 1998;64:192-203.

15 Borer JS, Fox K, Jaillon P, Lerebours G: Antianginal and antiischemic effects of ivabradine, an $\mathrm{I}_{\mathrm{f}}$ inhibitor, in stable angina: A randomized, double-blind, multicentered, placebo-controlled trial. Circulation 2003;107:817823.

16 Choong CY, Roubin GS, Harris PJ, Tokuyasu Y, Shen WF, Bautovich GJ, Kelly DT: A comparison of the effects of beta-blockers with and without intrinsic sympathomimetic activity on hemodynamics and left ventricular function at rest and during exercise in patients with coronary artery disease. J Cardiovasc Pharmacol 1986;8:441-448.

17 Reikeras O, Gunnes P: Effects of beta-receptor blockade on regional blood flows during acute left ventricular failure in dogs. J Cardiovasc Pharmacol 1987; 10:643-646.

18 Kostis JB, Frishman W, Hosler MH, Thorsen NL, Gonasun L, Weinstein J: Treatment of angina pectoris with pindolol: The significance of intrinsic sympathomimetic activity of betablockers. Am Heart J 1982;104:496-504. 
19 Bel A, Perrault LP, Faris B, Mouas C, Vilaine $\mathrm{J}-\mathrm{P}$, Menasche P: Inhibition of the pacemaker current: A bradycardic therapy for off-pump coronary operations. Ann Thorac Surg 1998; 66:148-152.

20 Brown HF, DiFrancesco D, Noble SJ: How does adrenaline accelerate the heart? Nature 1979;280:235-236.

21 DiFrancesco D, Mangoni M: Modulation of single hyperpolarization-activated channels $\left(\mathrm{I}_{\mathrm{f}}\right)$ by cAMP in the rabbit sino-atrial node. J Physiol 1994;474:473-482.
22 Moroni A, Barbuti A, Altomare C, Viscomi C, Morgan J, Baruscotti M, DiFrancesco D: Kinetic and ionic properties of the human $\mathrm{HCN} 2$ pacemaker channel. Pflugers Arch 2000;439: 618-626.

23 Cerbai E, Pino R, Rodriguez ML, Mugelli A: Modulation of the pacemaker current $I_{f}$ by beta-adrenoceptor subtypes in ventricular myocytes isolated from hypertensive and normotensive rats. Cardiovasc Res 1999;42:121129 .

24 Porciatti F, Pelzmann B, Cerbai E, Schaffer P, Pino R, Bernhart E, Koidl B, Mugelli A: The pacemaker current $I_{f}$ in single human atrial myocytes and the effect of beta-adrenoceptor and $\mathrm{A}_{1}$-adenosine receptor stimulation. $\mathrm{Br} \mathrm{J}$ Pharmacol 1997;122:963-969.
25 Kaneko A, Tachibana M: A voltage-clamp analysis of membrane currents in solitary bipolar cells dissociated from Carassius auratus. J Physiol 1985;358:131-152.

26 Demontis GC, Longoni B, Barcaro U, Cervetto $\mathrm{L}$ : Properties and functional roles of hyperpolarization-gated currents in guinea-pig retinal rods. J Physiol 1999;515:813-828.

27 Satoh TO, Yamada M: A bradycardiac agent ZD7288 blocks the hyperpolarization-activated current $\left(\mathrm{I}_{\mathrm{h}}\right)$ in retinal rod photoreceptors. Neuropharmacology 2000;39:1284-1291. 